\title{
Automated vs. conventional ventilation in the ICU: a randomized controlled crossover trial comparing blood oxygen saturation during daily nursing procedures (I-NURSING)
}

Jonathan Chelly ${ }^{1,2^{*}} \mathbb{D}$, Sandie Mazerand ${ }^{1}$, Sebastien Jochmans ${ }^{1,2}$, Claire-Marie Weyer ${ }^{1}$, Franck Pourcine ${ }^{1}$, Olivier Ellrodt ${ }^{1}$, Nathalie Thieulot-Rolin ${ }^{1}$, Jean Serbource-Goguel ${ }^{1}$, Oumar Sy ${ }^{1}$, Ly Van Phach Vong ${ }^{1}$ and Mehran Monchi ${ }^{1,2}$

\begin{abstract}
Background: Hypoxia is common during daily nursing procedures (DNPs) routinely performed on mechanically ventilated patients. The impact of automated ventilation on the incidence and severity of blood oxygen desaturation during DNPs remains unknown.

Methods: A prospective randomized controlled crossover trial was carried out in a French intensive care unit to compare blood oxygen pulse saturation $\left(\mathrm{SpO}_{2}\right)$ during DNPs performed on patients mechanically ventilated in automated and conventional ventilation modes ( $\mathrm{AV}$ and $\mathrm{CV}$, respectively). All patients with $\mathrm{FiO}_{2} \leq 60 \%$ and without prone positioning or neuromuscular blocking agents were included. Patients underwent two DNPs on the same day using AV (INTELLIVENT-ASV ${ }^{\circledR}$ ) and CV (volume control, biphasic positive airway pressure, or pressure support ventilation) in a randomized order. The primary outcome was the percentage of time spent with $\mathrm{SpO}_{2}$ in the acceptable range of $90-95 \%$ during the DNP.
\end{abstract}

Results: Of the 265 included patients, 93\% had been admitted for a medical pathology, the majority for acute respiratory failure (52\%). There was no difference between the two periods in terms of DNP duration, sedation requirements, or ventilation parameters, but patients had more spontaneous breaths and lower peak airway pressures during the AV period $(p<0.001)$. The percentage of time spent with $\mathrm{SpO}_{2}$ in the acceptable range during DNPs was longer in the AV period than in the CV period (48 \pm 37 vs. $43 \pm 37$, percentage of DNP period; $p=0.03$ ). After adjustment, $\mathrm{AV}$ was associated with a higher number of DNPs carried out with $\mathrm{SpO}_{2}$ in the acceptable range (odds ratio, $1.82 ; 95 \% \mathrm{Cl}, 1.28$ to 2.6; $p=0.001$ ) and a lower incidence of blood oxygen desaturation $\leq 85 \%$ (adjusted odds ratio, $0.50 ; 95 \% \mathrm{Cl}, 0.30$ to $0.85 ; p=0.01$ ).

(Continued on next page)

\footnotetext{
* Correspondence: jonathanchelly1@gmail.com

${ }^{1}$ Intensive Care Unit, Groupe Hospitalier Sud Ile de France, 270 avenue Marc Jacquet, 77000 Melun, France

${ }^{2}$ Clinical Research Unit, Groupe Hospitalier Sud Ile de France, 270 avenue

Marc Jacquet, 77000 Melun, France
}

(c) The Author(s). 2020 Open Access This article is licensed under a Creative Commons Attribution 4.0 International License, which permits use, sharing, adaptation, distribution and reproduction in any medium or format, as long as you give appropriate credit to the original author(s) and the source, provide a link to the Creative Commons licence, and indicate if changes were made. The images or other third party material in this article are included in the article's Creative Commons licence, unless indicated otherwise in a credit line to the material. If material is not included in the article's Creative Commons licence and your intended use is not permitted by statutory regulation or exceeds the permitted use, you will need to obtain permission directly from the copyright holder. To view a copy of this licence, visit http://creativecommons.org/licenses/by/4.0/ The Creative Commons Public Domain Dedication waiver (http://creativecommons.org/publicdomain/zero/1.0/) applies to the data made available in this article, unless otherwise stated in a credit line to the data. 
(Continued from previous page)

Conclusion: AV appears to reduce the incidence and severity of blood oxygen desaturation during daily nursing procedures (DNPs) in comparison to CV.

Trial registration: This study was registered in clinical-trial.gov (NCT03176329) in June 2017.

Keywords: Mechanical ventilation, Automated ventilation, Nursing procedure

\section{Background}

Daily nursing procedures (DNPs) are routinely performed several times per day in the intensive care unit (ICU) and are crucial for patients' hygiene and rehabilitation, and to prevent/treat complications due to immobilization [1-4]. However, these DNPs induce physiological changes with potential adverse effects, especially in patients undergoing mechanical ventilation (MV) [5-9]. Respiratory events, in particular oxygen desaturation, are often observed during DNPs but are not well documented [10]. Although the potential adverse effects may be serious (e.g., severe hypoxemia and cardiac arrest), these events are often downplayed, considered as a normal part of DNPs, or ignored in interventional studies regarding MV in ICU patients [10]. As suggested by previous works, protocols should be developed to prevent such respiratory events $[11,12]$. INTELLiVENT-ASV $^{\bullet}$ (Hamilton Medical, Bonaduz, Switzerland) is an automated ventilation mode (AV) that automatically adjusts ventilation and oxygenation settings to keep end-tidal $\mathrm{CO}_{2}\left(\mathrm{PetCO}_{2}\right)$ and $\mathrm{SpO}_{2}$ in target ranges set by the clinician [13]. Briefly, minute volume is adjusted according to $\mathrm{PetCO}_{2}$ information or respiratory rate in passive or spontaneously breathing patients respectively and $\mathrm{FiO} 2$ and PEEP are adjusted according to blood oxygen pulse saturation $\left(\mathrm{SpO}_{2}\right)$ information. The safety, feasibility, and efficacy of this mode have been demonstrated with promising results that show a reduction in both the number of manual interventions needed and the incidence of blood oxygen desaturation for various patient conditions, including acute respiratory failure, post-cardiac surgery, and weaning from MV [13-20]. To our knowledge, however, no study has assessed the impact of $\mathrm{AV}$ on the incidence of respiratory events during DNPs. The aim of our study was to compare the incidence and severity of blood oxygen desaturation during DNPs performed on patients ventilated in $\mathrm{AV}$ and in conventional ventilation mode $(\mathrm{CV})$.

\section{Methods}

\section{Settings and patients}

This single-center randomized controlled crossover study was conducted from September 2016 to March 2018 in a 22-bed, mixed ICU of a French tertiary center. All patients of both sexes mechanically ventilated for at least $48 \mathrm{~h}$ with a fraction of inspired oxygen $\left(\mathrm{FiO}_{2}\right) \leq 60 \%$ were included. Exclusion criteria were prone positioning, use of neuromuscular blocking agents, age $<18$ years old, pregnant women, patients with a contraindication to AV (delirium, broncho-pleural fistula, respiratory drive disorder such as Cheyne-Stokes breathing), and patients with a low-quality measurement for $\mathrm{SpO}_{2}$. The study was initiated and supported by the Groupe Hospitalier Sud Ile de France (Melun, France). The study protocol was approved on the 13th of September 2016 by the ethical committee (Comité de Protection des Personnes Ile de France VI) and registered in ClinicalTrials.gov (NCT03176329). Patients or their next-of-kin gave their informed consent before randomization.

\section{Study protocol and data collection}

All included patients were ventilated using a HAMI LTON-S1 ventilator (Hamilton Medical, Bonaduz, Switzerland) and $\mathrm{SpO}_{2}$ was monitored using a dedicated sensor (Masimo $\mathrm{SET}^{\circ}$, Masimo Corporation, Irvine, USA) connected to the patient's monitor (Beneview $\mathrm{T} 8^{\circ}$, Mindray, Shenzhen, China). After randomization, each patient underwent two DNPs on the same day, with $6 \mathrm{~h}$ between the two. One was performed in $\mathrm{CV}$ and the other in AV in a randomized order defined at inclusion. DNPs were performed by two nurses and included a bundle of care covering patient hygiene (bathing, change of bed linen), mobilization (repositioning), ventilatorassociated pneumonia prevention (oral hygiene care, subglottic secretion drainage, adjustment of endotracheal tube cuff pressure), and pressure ulcer prevention and treatment (massage of back and pressure points). All the patient's monitoring and ventilation parameters, including heart rate, mean arterial pressure, $\mathrm{SpO}_{2}, \mathrm{FiO}_{2}$, expiratory tidal volume, total and spontaneous respiratory rate, positive end-expiratory pressure (PEEP), and inspiratory and mean airway pressure, were automatically recorded every minute during the DNP using Evolucare Intensive 6.4 ${ }^{\circ}$ (Evolucare Technologies, Villers-Bretonneux, France). Arterial blood gas samples were performed $5 \mathrm{~min}$ before each DNP to determine the $\mathrm{PaO}_{2} / \mathrm{FiO}_{2}$ ratio. All events that occurred during the DNPs, such as blood oxygen desaturation, change of ventilation mode, accidental disconnection of the ventilator, the need for manual ventilation, activation of an oxygen bypass, or endotracheal suctioning, were also reported by the nurse in charge. 


\section{Ventilation settings}

At least 30 min before each of the two DNPs, the attending physician set the MV mode according to the randomized order. For the CV period, the mode and ventilator settings were selected by the attending physician according to patient's pathologies and conditions: either volume control (VC), biphasic positive airway pressure (BIPAP), or pressure-support ventilation (PSV). In VC mode, the tidal volume $\left(V_{T}\right)$ was set below $7 \mathrm{~mL} /$ $\mathrm{kg}$ predicted body weight (PBW) for acute respiratory distress syndrome, below $9 \mathrm{~mL} / \mathrm{kg}$ PBW for subjects with normal lungs, and below $11 \mathrm{~mL} / \mathrm{kg}$ PBW for subjects with chronic obstructive pulmonary disease. In BIPAP and PSV, inspiratory pressure and pressure support were set according to the same $V_{T}$ limits as in VC. Plateau pressure was limited to $30 \mathrm{cmH}_{2} \mathrm{O}$, while positive endexpiratory pressure (PEEP) and $\mathrm{FiO}_{2}$ were set to maintain $\mathrm{SpO}_{2}$ before the DNPs at between 94 and 98\% [21, 22]. During the DNPs, nurses were responsible for maintaining $\mathrm{SpO}_{2}$ within an acceptable range of $90-95 \%$ by adjusting the $\mathrm{FiO}_{2}$ setting. The basic principles of INTE LLiVENT-ASV $^{\circ}$ are detailed as previously described [13] in the Online supplemental content 1. Before the DNP in $\mathrm{AV}$, automated $\mathrm{FiO}_{2}$ and PEEP controllers were set by the attending physician with a lower limit for $\mathrm{SpO}_{2}$ at 90\% and a PEEP limited to 5-15 $\mathrm{cmH}_{2} \mathrm{O}$. The high limit for airway pressure was set at a maximum of $30 \mathrm{cmH}_{2} \mathrm{O}$. For both DNPs, alarm limits were set by the clinicians. In the case of major blood oxygen desaturation $\left(\mathrm{SpO}_{2} \leq\right.$ $85 \%$ according to guidelines [22]), the nurse in charge was required to apply a specific protocol (see Online supplemental content 2) and a physician was always present in the ICU in case a problem persisted. Sedation infusion, inspiratory trigger, pressure rise, expiratory trigger, and ventilator circuit were the same in both periods.

\section{Study outcomes}

The primary outcome was the time spent with $\mathrm{SpO}_{2}$ values of $90-95 \%$ (considered to be the acceptable $\mathrm{SpO}_{2}$ range during the DNP). Secondary outcomes were as follows: Incidence of $\mathrm{SpO}_{2}$ in the acceptable range during the DNP; mean, minimum, and maximum $\mathrm{SpO}_{2}$ during the DNP $\left(\mathrm{SpO}_{2}\right.$ mean, $\mathrm{SpO}_{2}$ min , and $\mathrm{SpO}_{2}$ max , respectively); incidence and time spent with $\mathrm{SpO}_{2}$ lower than 90\%; incidence and time spent with $\mathrm{SpO}_{2}$ lower than 85\%; and time spent with $\mathrm{FiO}_{2}$ at $100 \%$. The safety outcome parameters were the occurrence of major adverse events (accidental endotracheal tube removal, bradycardia lower than $40 \mathrm{bpm}$, or cardiac arrest) during the DNP. Two interim analyses for primary and safety outcome parameters were planned after 90 and 180 patients were enrolled.

\section{Statistical analysis}

Based on previous studies on DNPs $[9,10]$ and retrospective data collected in our institution, we estimated that patients spent $40 \%$ of the DNP duration with $\mathrm{SpO}_{2}$ between 90 and $95 \%$. We calculated a sample size of 267 patients by group to detect a $15 \%$ increase in the primary outcome for DNPs performed in AV as compared to $\mathrm{CV}$ (2-sided $\alpha=0.05$; power $80 \%$ ). Continuous variables are expressed by mean \pm standard deviation and nominal variables as $n$ (\%). Continuous variables were compared using the non-parametric Wilcoxon test and nominal variables were compared using Fisher's exact test. After a univariate analysis to assess all risk factors for primary and secondary outcomes, a multivariate analysis was performed including all univariate factors with $p<0.15$. Differences were considered significant where $p<0.05$. All calculations were performed using SPSS Statistics V20 ${ }^{\circ}$ (IBM, New York, USA).

\section{Results}

There were no safety issues that required premature interruption. Among the 465 patients assessed for eligibility, 185 were excluded, leaving 280 for inclusion (Fig. 1). Fifteen patients in both periods were subsequently excluded from the analysis due to recording failure, resulting in 265 patients with one DNP in each period for the final analysis.

\section{Patient characteristics}

Baseline characteristics of the overall cohort are detailed in Table 1. Patients were primarily admitted for a medical pathology $(92 \%)$ and half were intubated for acute respiratory failure (52\%). The mean time of MV before inclusion and the total MV duration were $4 \pm 4$ and $11 \pm$ 8 days, respectively. Of the 265 patients, 201 (76\%) were successfully weaned from MV and 74 (28\%) died before ICU discharge. The interval between both DNPs was $406 \pm 118 \mathrm{~min}$. Before the DNP, $\mathrm{SpO}_{2}$ was significantly lower in AV than in CV $(95 \pm 3 \%$ vs. $96 \pm 3 \%$, respectively; $p<0.001$ ), whereas $\mathrm{PaO}_{2} / \mathrm{FiO}_{2}$ and $\mathrm{SpO}_{2} / \mathrm{FiO}_{2}$ were similar ( $p=0.10$ and 0.49 , respectively). DNP duration varied from 2 to $55 \mathrm{~min}$ in the overall cohort. As detailed in Table 2, DNP duration and patient sedation levels were similar during both periods, as were hemodynamic parameters, tidal volume, total breathing rate, and PEEP level. During the $\mathrm{CV}$ period, BIPAP mode was largely used (87\%) and patients had a significantly lower spontaneous breathing rate than during the AV period (14 \pm 11 vs. $22 \pm 12$ breath/min, respectively; $p<0.001)$. Patients had a lower peak airway pressure ( $25 \pm 7$ vs. $27 \pm 6 \mathrm{cmH}_{2} \mathrm{O} ; p<0.001$ ) and mean airway pressure $(14 \pm 4$ vs. $15 \pm 4 \mathrm{cmH} 2 \mathrm{O} ; p<0.001)$ during the $\mathrm{AV}$ period than during the $\mathrm{CV}$ period. 


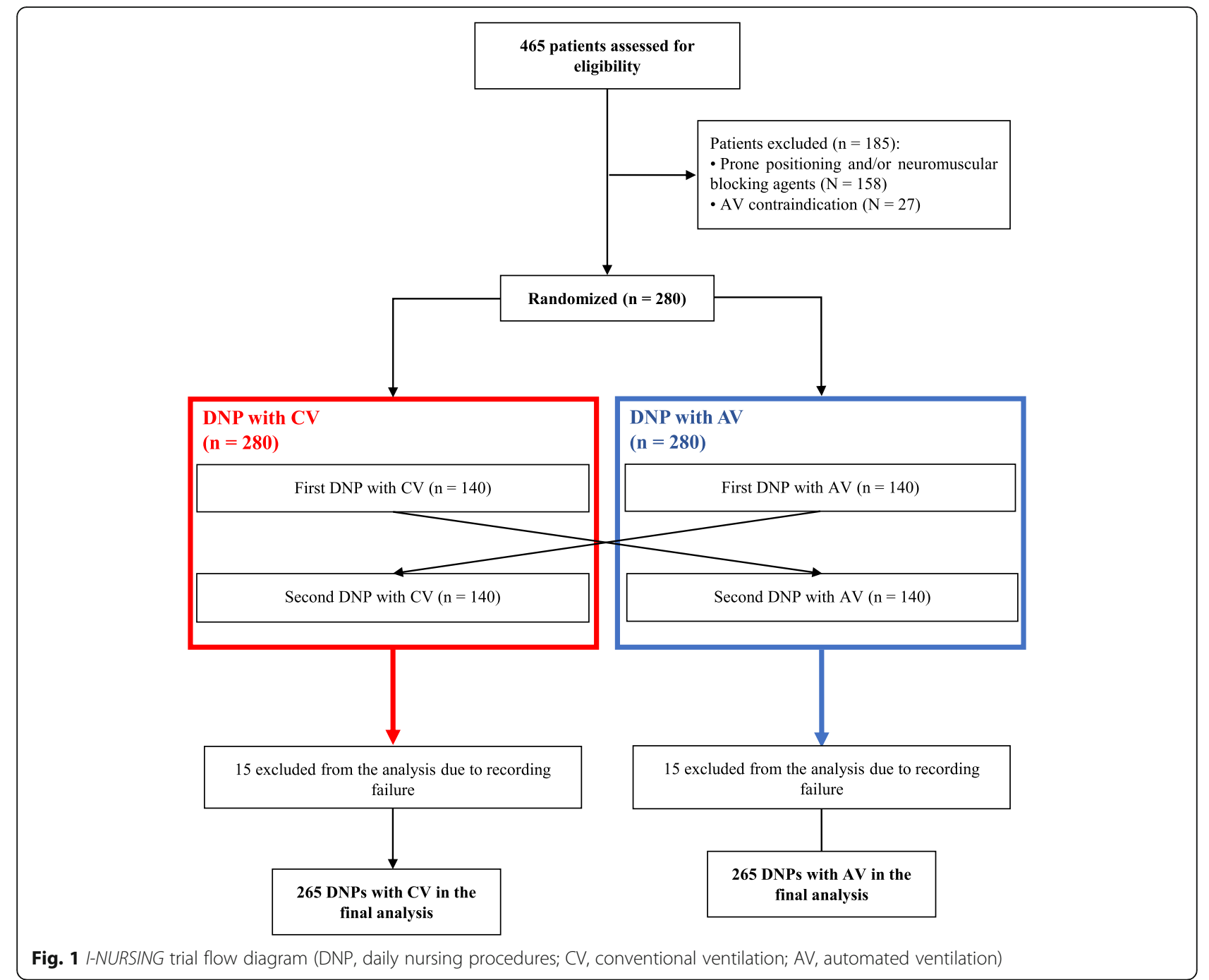

\section{Endpoints}

Data for the primary and secondary endpoints are provided in Table 3. Patients spent significantly more time in the acceptable $\mathrm{SpO}_{2}$ range during the $\mathrm{AV}$ period (48 \pm 37 vs. $43 \pm 37 \%$ of DNP period; $p=0.03$ ). In 160 patients $(60 \%), \mathrm{SpO}_{2}$ was in the acceptable range during the AV period as compared to 123 patients (46\%) during the CV period $(p=0.001)$. After adjustment for confounding factors, AV was associated with a greater number of DNPs performed with $\mathrm{SpO}_{2}$ in the acceptable range (odds ratio [OR], 1.82; 95\% confidence interval [CI], 1.28 to $2.6 ; p=0.001$; see Online supplemental content 3$)$. In the overall cohort, blood oxygen desaturation to levels $<90 \%$ and $\leq 85 \%$ occurred in $161(30 \%)$ and 80 (15\%) patients, respectively. Incidences of blood oxygen desaturation to lower than $90 \%$ were less frequent during the AV period than during the CV period (69 [26\%] vs. 92 [35\%], episodes $>1 \mathrm{~min} ; p=0.03$ ) and were also shorter $(5 \pm 12$ vs. $6 \pm 11$, \% of DNP period; $p=0.02)$.
Incidences of major blood oxygen desaturation $(\leq 85 \%)$ were less frequent during the $\mathrm{AV}$ period than during the CV period (30 [11\%] vs. 50 [19\%], episodes $>1 \mathrm{~min} ; p=$ $0.02)$ and were also shorter ( $2 \pm 6$ vs $3 \pm 8$, percentage of DNP period; $p=0.03$ ). After adjustment for confounding factors, AV was associated with a lower incidence of blood oxygen desaturation $\leq 85 \%$ during DNPs (OR, 0.50 ; $95 \% \mathrm{CI}, 0.30$ to $0.85 ; p=0.01$; see Online supplemental content 4). As shown in Fig. 2, more patients had $\mathrm{SpO}_{2 \min }$ in the optimal range during the $\mathrm{AV}$ period $(p=0.02)$, while more patients had the $\mathrm{SpO}_{2 \min } \leq 85 \%$ during the CV period $(p=0.002)$. There was no difference between the two periods for the other secondary endpoints (Table 3).

\section{Nurse/physician/ventilator interventions, safety, and major adverse events}

All the unplanned interventions performed by a nurse or physician during DNPs are detailed in the Online 
Table 1 Patients' baseline characteristics at inclusion

\begin{tabular}{|c|c|}
\hline Characteristics & $\begin{array}{l}\text { Overall cohort } \\
n=265\end{array}$ \\
\hline Age-years & $64 \pm 14(62-66)$ \\
\hline Men/women—n (\%) & $172(65 \%) / 93(35 \%)$ \\
\hline Body mass index- $\mathrm{kg} / \mathrm{m}^{2}$ & $31 \pm 15(29-32)$ \\
\hline \multicolumn{2}{|l|}{ Chronic disease $-n(\%)$} \\
\hline COPD & $55(21 \%)$ \\
\hline Chronic respiratory failure & $26(10 \%)$ \\
\hline Chronic heart failure & $34(13 \%)$ \\
\hline SAPS-2 at ICU admission & $59 \pm 19(56-61)$ \\
\hline SOFA at inclusion & $9 \pm 3(8-9)$ \\
\hline \multicolumn{2}{|l|}{ Reason for ICU admission—n (\%) } \\
\hline Medical & $245(92 \%)$ \\
\hline Surgical & $20(8 \%)$ \\
\hline Acute organ failure at inclusion $-n(\%)$ & $178(67 \%)$ \\
\hline Hemodynamic & $122(46 \%)$ \\
\hline Kidney & $57(22 \%)$ \\
\hline Neurologic & $42(16 \%)$ \\
\hline Heart & $25(9 \%)$ \\
\hline Liver & $22(8 \%)$ \\
\hline Hematologic & $9(3 \%)$ \\
\hline \multicolumn{2}{|l|}{ Main reason for $\mathrm{MV} — n(\%)$} \\
\hline Acute respiratory failure & $138(52 \%)$ \\
\hline Coma & $67(25 \%)$ \\
\hline Cardiac arrest & $19(7 \%)$ \\
\hline Sepsis & $15(6 \%)$ \\
\hline Other & $24(9 \%)$ \\
\hline Unknown & $2(1 \%)$ \\
\hline MV duration before inclusion—days & $4 \pm 4(4-5)$ \\
\hline Chest radiograph opacities_-quadrants & $2 \pm 1(1-2)$ \\
\hline
\end{tabular}

Categorical variables are expressed as $n$ (\%) and continuous variables as mean \pm standard deviation ( $95 \%$ confidence interval)

COPD chronic obstructive pulmonary disease, SAPS-2 Simplified Acute Physiological Score 2, SOFA Sepsis-Related Organ Failure Assessment, ICU intensive care unit, $M V$ mechanical ventilation

supplement content 5. A change of ventilation mode occurred in only one patient in each period, and two patients required manual ventilation in the $\mathrm{CV}$ period. Patients required fewer manual activations of an oxygen bypass during the AV period than during the $\mathrm{CV}$ period (41 [15\%] vs. 69 [26\%]; $p=0.004)$ and less endotracheal suctioning per DNP ( $1 \pm 0$ vs $1 \pm 1 ; p=0.03)$. PEEP was manually increased in two patients (1\%) during the CV period and automatically increased by the ventilator in 53 patients (20\%) during the AV period. With the exception of one episode of bradycardia $(<40 \mathrm{bpm})$ in one patient during the AV period, no major adverse events occurred during DNPs in either period. Accidental disconnection of the ventilator occurred in 18 (7\%) and 16
(6\%) patients during the AV and CV periods, respectively $(p=0.9)$.

\section{Discussion}

This is the first study to test the ability of AV to reduce the occurrence of oxygen desaturation during DNPs routinely performed in ICU patients undergoing MV. In this randomized crossover trial, the use of AV (in this case INTELLiVENT ${ }^{\circ}$-ASV ${ }^{\circ}$ ) was superior to $\mathrm{CV}$ with respect to maintaining $\mathrm{SpO} 2$ within an acceptable range and reducing the incidence and severity of oxygen desaturation.

Although ICU nurses and physicians frequently observe blood oxygen desaturation relating to DNPs in their daily practice, these respiratory events remain poorly documented. In a cohort of 53 ICU patients (including 45\% under MV), De Jong et al. observed blood oxygen desaturation $\leq 90 \%$ and ventilatory distress (severe patient-ventilator asynchrony, nonstop coughing, impossible ventilation, and/or tachypnea) in 10 and 13\%, respectively, of the 184 DNPs performed [9]. In a prospective study on 16 ICU patients undergoing MV, 668 nursing procedures were observed and blood oxygen desaturation $\leq 90 \%$ was the most frequent adverse event described, representing $29 \%$ of the overall major physiological changes reported by the authors [10]. For our overall cohort, we reported blood oxygen desaturation < 90 and $\leq 85 \%$ during DNPs in 30 and 15\%, respectively.

Various physiological changes may be implicated by the occurrence of blood oxygen desaturation during DNPs. Patient mobilization is one of the most important, and in particular lateralization, which can induce a decrease in lung compliance, alveolar derecruitment, mobilization of respiratory-tract secretions, airway irritations and coughing, ventilator-patient asynchrony $[10,23-26]$, and an increase in oxygen consumption $[5,6]$. All those physiological events could be induced by mobilization itself and/or the stress response associated with pain [10, 27-29].

The impact on patient outcomes of DNPs and their related adverse events remains unclear. Previous studies have suggested that early mobilization of the patient would be associated with a greater chance of achieving rehabilitation objectives in the ICU setting [1-4]. De Jong et al. observed an incidence of cardiac arrest in 1\% of the DNPs performed, while we did not report any incidence of cardiac arrest or death related to DNPs in our overall cohort.

Our study suggests AV may have a protective effect when compared to $\mathrm{CV}$ in terms of $\mathrm{SpO}_{2}$ values and the incidence and severity of blood oxygen desaturation during DNPs. A prospective randomized controlled study of 60 post-cardiac surgery patients showed that in comparison to $\mathrm{CV}$, INTELLiVENT-ASV ${ }^{\odot}$ significantly reduces 
Table 2 General, hemodynamic and ventilation parameters during daily nursing procedure (DNPS) according to ventilation mode (CV conventional ventilation, AV automated ventilation)

\begin{tabular}{|c|c|c|c|}
\hline Parameters & $\begin{array}{l}\text { CV period } \\
n=265\end{array}$ & $\begin{array}{l}\text { AV period } \\
n=265\end{array}$ & $p$ \\
\hline \multicolumn{4}{|l|}{ DNP parameters } \\
\hline DNPs duration-min & $12 \pm 6(11-13)$ & $12 \pm 8(11-13)$ & 0.95 \\
\hline Ramsay score & $4 \pm 2(4-4)$ & $4 \pm 1(4-4)$ & 0.35 \\
\hline \multicolumn{4}{|l|}{ Oxygenation before DNPs } \\
\hline $\mathrm{SpO}_{2}-\% *$ & $96 \pm 3(95-96)$ & $95 \pm 3(95-95)$ & $<0.001$ \\
\hline $\mathrm{SpO}_{2} / \mathrm{FiO}_{2}{ }^{*}$ & $320 \pm 79(310-329)$ & $317 \pm 87(306-327)$ & 0.49 \\
\hline $\mathrm{PaO}_{2} / \mathrm{FiO}_{2}^{* *}$ & $268 \pm 95(255-282)$ & $266 \pm 92(253-280)$ & 0.10 \\
\hline \multicolumn{4}{|l|}{ Hemodynamics during DNPs } \\
\hline Heart rate- bpm † & $98 \pm 19(95-100)$ & $98 \pm 20(96-101)$ & 0.32 \\
\hline Mean arterial pressure $-\mathrm{mmHg}^{\dagger}$ & $89 \pm 14(87-90)$ & $88 \pm 15(86-90)$ & 0.56 \\
\hline \multicolumn{4}{|l|}{ Ventilation during DNPs } \\
\hline \multicolumn{4}{|l|}{ Mode used in the CV period $-n(\%)$} \\
\hline Biphasic positive airway pressure & $230(87 \%)$ & - & - \\
\hline Pressure support ventilation & $23(9 \%)$ & - & - \\
\hline Volume controlled & $12(4 \%)$ & - & - \\
\hline Tidal volume $-\mathrm{mL} / \mathrm{kg}$ of $\mathrm{PBW}^{+}$ & $10 \pm 3(10-10)$ & $10 \pm 2(10-10)$ & 0.40 \\
\hline Total RR—breath/min ${ }^{\dagger}$ & $28 \pm 9(27-29)$ & $27 \pm 8(26-28)$ & 0.79 \\
\hline Spontaneous RR—breath/min ${ }^{\dagger}$ & $14 \pm 11(13-15)$ & $22 \pm 12(21-24)$ & $<0.001$ \\
\hline Passive ventilation $-n(\%)^{* * *}$ & $35(13 \%)$ & $9(3 \%)$ & $<0.001$ \\
\hline Peak airway pressure $-\mathrm{CmH}_{2} \mathrm{O}^{+}$ & $27 \pm 6(26-27)$ & $25 \pm 7(24-26)$ & $<0.001$ \\
\hline Mean airway pressure $-\mathrm{cmH}_{2} \mathrm{O}^{+}$ & $15 \pm 4(14-15)$ & $14 \pm 4(14-15)$ & $<0.001$ \\
\hline $\mathrm{PEEP}-\mathrm{cmH}_{2} \mathrm{O}^{\dagger}$ & $9 \pm 3(9-10)$ & $9 \pm 3(9-10)$ & 0.07 \\
\hline
\end{tabular}

Categorical variables are expressed as $n$ (\%) and continuous variables as mean \pm standard deviation (95\% confidence interval)

$P B W$ predicted body weight, $R R$ respiratory rate, $P e t C O_{2}$ end-tidal $\mathrm{CO}_{2}$ partial pressure, $P E E P$ positive end-expiratory pressure

*Measured the minute before starting the DNP

**Measured 5 min before starting the DNP

***Defined as no spontaneous breathing detected by the ventilator

${ }^{+}$Mean of the overall parameters monitored every minute during the DNP

the percentage of time, as well as the total duration and number of episodes per patient of ventilation parameters (including tidal volume, $\mathrm{EtCO}_{2}$, plateau pressure, and $\mathrm{SpO}_{2}$ ) being within a "not acceptable" zone [14]. During the weaning period in 16 ICU patients, INTELLiVENT$\mathrm{ASV}^{\circ}$ improved the $\mathrm{PaO}_{2} / \mathrm{FiO}_{2}$ ratio compared to PSV [15]. In accordance with our results, another randomized trial including $80 \mathrm{ICU}$ patients showed that INTELLiVENT-ASV ${ }^{\bullet}$ was superior to pressure assist-control and PSV for maintaining $\mathrm{SpO}_{2}$ in an optimal range defined by the authors as between 92 and 96\% [18].

The positive results of AV on the incidence of blood oxygen desaturation may be explained by many factors: INTELLiVENT-ASV ${ }^{\bullet}$ continuously and quickly adapts oxygenation, increasing PEEP and $\mathrm{FiO}_{2}$ when $\mathrm{SpO}_{2}$ decreases, but also by automatically decreasing PEEP and $\mathrm{FiO}_{2}$ when $\mathrm{SpO}_{2}$ is supranormal. In contrast, nurses and physicians are not able to adjust $\mathrm{FiO}_{2}$ every time while they are providing care, especially during mobilization of a patient. As suggested by our results, the need for endotracheal suctioning during DNPs seems less frequent in $\mathrm{AV}$, which could be interpreted as the cause or the consequence of a lower incidence of blood oxygen desaturation.

\section{Limitations of the study}

Several factors may limit the interpretation of our data. First, this was a single-center study in a single-blinded design, carried out in an ICU staffed by nurses and physicians considered as advanced users of AV. However, previous studies have consistently reported on the efficacy and safety advantages of using AV over CV [13-20]. Second, patients in unstable respiratory conditions, such as high $\mathrm{FiO} 2>60 \%$ with or without the use of neuromuscular blocking agents and/or with prone positioning, were excluded from the study. In our ICU, as is general practice in many ICUs, DNPs in patients with unstable respiratory conditions are delayed until the patient's condition 
Table 3 Primary and secondary outcome parameters according to ventilation mode (CV conventional ventilation, AV automated ventilation)

\begin{tabular}{|c|c|c|c|}
\hline Outcome parameters & $\begin{array}{l}\text { CV period } \\
n=265\end{array}$ & $\begin{array}{l}\text { AV period } \\
n=265\end{array}$ & $p$ \\
\hline \multicolumn{4}{|l|}{ Primary outcome } \\
\hline Time spent with $\mathrm{SpO}_{2}$ in the acceptable range-\% of DNP duration* & $43 \pm 37(38-47)$ & $48 \pm 37(43-52)$ & 0.03 \\
\hline \multicolumn{4}{|l|}{ Secondary outcome } \\
\hline Patients with $\mathrm{SpO}_{2}$ in the acceptable range during $\mathrm{DNP}-n(\%)^{*}$ & $123(46 \%)$ & $160(60 \%)$ & 0.001 \\
\hline \multicolumn{4}{|l|}{ Patients with at least one episode of: } \\
\hline $\mathrm{SpO}_{2} \leq 85 \% \%^{* *}-n(\%)$ & $50(19 \%)$ & $30(11 \%)$ & 0.02 \\
\hline $\mathrm{SpO}_{2}<90 \%{ }^{* *}-n(\%)$ & $92(35 \%)$ & $69(26 \%)$ & 0.03 \\
\hline \multicolumn{4}{|l|}{ Time spent with: } \\
\hline $\mathrm{SpO}_{2} \leq 85 \%$ - $\%$ of DNP duration & $3 \pm 8(2-4)$ & $2 \pm 6(1-2)$ & 0.03 \\
\hline $\mathrm{SpO}_{2}<90 \%$ - $\%$ of DNP duration & $6 \pm 11(5-7)$ & $5 \pm 12(3-6)$ & 0.02 \\
\hline $\mathrm{FiO}_{2} 100 \%$ - $\%$ of DNP duration & $6 \pm 12(4-7)$ & $4 \pm 10(3-6)$ & 0.09 \\
\hline $\mathrm{SpO}_{2 \text { mean }} \%$ & $95 \pm 3(95-95)$ & $95 \pm 3(95-95)$ & 0.81 \\
\hline $\mathrm{SpO}_{2} \min -\%$ & $91 \pm 6(90-91)$ & $91 \pm 8(90-92)$ & 0.20 \\
\hline $\mathrm{SpO}_{2 \max }-\%$ & $97 \pm 2(97-98)$ & $97 \pm 2(97-98)$ & 0.63 \\
\hline
\end{tabular}

Categorical variables are expressed as $n(\%)$ and continuous variables as mean \pm standard deviation (95\% confidence interval)

DNP daily nursing procedure, $\mathrm{SpO}_{2}$ blood oxygen pulse saturation, $\mathrm{FiO}_{2}$ fraction of inspired oxygen, $\mathrm{SpO}_{2}$ mean mean $\mathrm{SpO}_{2}$ during $\mathrm{DNP}_{\text {, }} \mathrm{SpO} \mathrm{O}_{2}$ min minimal $\mathrm{SpO} \mathrm{O}_{2}$ recorded during DNP, $\mathrm{SpO}_{2}$ max maximal $\mathrm{SpO}_{2}$ recorded during DNP

* $\mathrm{SpO}_{2}$ acceptable range was $\geq 90$ and $\leq 95 \%$

**For more than 1 min

improves or performed with $\mathrm{FiO}_{2}$ set at $100 \%$ by default. Third, we should have systematically assessed and prevented pain related to patient's care. Indeed, the incidence of respiratory events decrease significantly with the application of an analgesic protocol before and during DNP, as previously described by De Jong et Al. Future studies on DNP should take pain prevention and treatment into account [9]. Moreover, we cannot draw any conclusions with respect to a protective or harmful effect of AV in terms of ventilator-induced lung injury (VILI) during DNPs. Tidal volumes were higher than the initial setting for both periods, probably due to an increase in the patient's ventilatory drive during mobilization (induced by stress, pain, etc.). However, inspiratory pressure was lower and spontaneous breathing was higher during DNPs in
AV. Future studies are needed to assess mechanical power and the risk of VILI during DNPs [30]. Fourth, we may have underestimated the incidence of short oxygen desaturation $(<1 \mathrm{~min})$ because we have not performed a breath by breath monitoring. Fifth, the accuracy of $\mathrm{SpO}_{2}$ measurements remains controversial, particularly in ICU patients with acute organ failure, as previously observed [31]. However, blood gas samples are not easy to perform during DNP and $\mathrm{SpO}_{2}$ represents the only parameters to assess oxygenation at bedside during this procedure. Finally, although we found a significant difference in the primary outcome in favor of AV during DNPs, the clinical impact remains unknown. Further studies are warranted to confirm our results and to assess the real impact on patient outcomes and management.
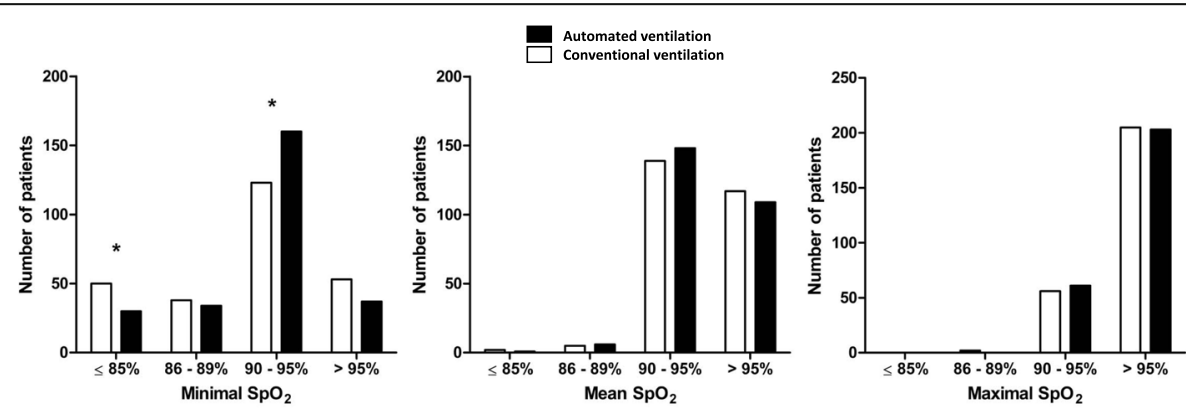

Fig. 2 Comparison between conventional and automated ventilation in terms of minimal, mean, and maximal blood oxygen saturation ( $\mathrm{SpO}_{2}$ ) during daily nursing procedures $\left({ }^{*} p<0.05\right)$ 


\section{Conclusion}

AV used during DNPs routinely performed on ICU patients undergoing $\mathrm{MV}$ appears to be superior to $\mathrm{CV}$ in maintaining $\mathrm{SpO}_{2}$ within an acceptable range and reducing the incidence and severity of desaturation, with more spontaneous breathing and lower peak and mean airway pressure.

\section{Supplementary information}

Supplementary information accompanies this paper at https://doi.org/10. 1186/s13054-020-03155-3.

Additional file 1: Online supplemental content 1. Basic principles of INTELLIVENT-ASV ${ }^{\circledR}$. Supplemental content 2. Protocol for nurses in case of major blood oxygen desaturation $\left(\mathrm{SpO}_{2} \leq 85 \%\right)$ during the daily nursing procedure (DNP). Supplemental content 3. Multivariate logistic regression test for $\mathrm{SpO}_{2}$ in the acceptable range (between 90\% and 95\%) during the daily nursing procedure (DNP). Supplemental content 4. Multivariate logistic regression test of risk factors for occurrence of at least one major oxygen desaturation $\left(\mathrm{SpO}_{2} \leq 85 \%\right)$ during the daily nursing procedure (DNP). Supplemental content 5. Nurse/physician interventions during the daily nursing procedure (DNP) according to ventilation mode (CV conventional ventilation; $A V$ automated ventilation)

\section{Abbreviations}

AV: Automated ventilation mode; BIPAP: Biphasic positive airway pressure Cl: Confidence interval; CV: Conventional ventilation mode; DNP: Daily nursing procedure; $\mathrm{FiO}_{2}$ : Fraction of inspired oxygen; ICU: Intensive care unit; MV: Mechanical ventilation; PEEP: Positive end-expiratory pressure; $\mathrm{PetCO}_{2}$ : End-tidal $\mathrm{CO}_{2}$ partial pressure; PSV: Pressure support ventilation; $\mathrm{SpO}_{2}$ : Blood oxygen pulse saturation; VC: Volume control; VILI: Ventilatorinduced lung injury

\section{Acknowledgements}

We are indebted to Caroline Huber-Brown for editorial assistance.

\section{Authors' contributions}

All authors have contributed to the final version of the manuscript as follows: JC and SJ contributed to the study concept and design; JC, SM, SJ, CW, FP, OE, NT, JS, OS, and LV contributed to patient's inclusion; JC and SM contributed to data collection; JC and SJ contributed to data analysis; and JC, SJ, and MM drafted and revised the manuscript. The authors read and approved the final manuscript.

\section{Funding}

The study was integrally supported by the Groupe Hospitalier Sud Ile de France (Melun, France)

\section{Availability of data and materials}

The dataset used and/or analyzed during the current study are available from the corresponding author on reasonable request.

\section{Ethics approval and consent to participate}

The study protocol was approved on the 13th of September 2016 by the ethical committee (Comité de Protection des Personnes Ile de France VI; ID number 2016-A00569-42) and registered in clinical-trial.gov (NCT03176329). Patient or their next-of-kin gave their informed consent before randomization

\section{Consent for publication}

Not applicable

\section{Competing interests}

$\mathrm{JC}$ and $\mathrm{SJ}$ received fees from Hamilton Medical for lecturing. The remaining authors declare that they have no competing interests.
Received: 21 February 2020 Accepted: 5 July 2020

Published online: 22 July 2020

\section{References}

1. Hall JB. Creating the animated intensive care unit. Crit Care Med. 2010;38: S668-75.

2. Denehy L, Elliott D. Strategies for post ICU rehabilitation. Curr Opin Crit Care. 2012;18:503-8.

3. Krishnagopalan S, Johnson EW, Low LL, Kaufman LJ. Body positioning of intensive care patients: clinical practice versus standards. Crit Care Med. 2002:30:2588-92.

4. Goldhill DR, Badacsonyi A, Goldhill AA, Waldmann C. A prospective observational study of ICU patient position and frequency of turning. Anaesthesia. 2008;63:509-15

5. Jakob SM, Parviainen I, Ruokonen E, Hinder R, Uusaro A, Takala J. Increased splanchnic oxygen extraction because of routine nursing procedures. Crit Care Med. 2009;37:483-9.

6. Jones AYM, Dean E. Body position change and its effect on hemodynamic and metabolic status. Heart Lung J Crit Care. 2004;33:281-90.

7. Nyholm L, Steffansson E, Frojd C, Enblad P. Secondary insults related to nursing interventions in neurointensive care: a descriptive pilot study. J Neurosci Nurs J Am Assoc Neurosci Nurses. 2014:46:285-91.

8. Tume LN, Baines PB, Lisboa PJG. The effect of nursing interventions on the intracranial pressure in paediatric traumatic brain injury. Nurs Crit Care. 2011 16:77-84

9. de Jong A, Molinari N, de Lattre S, Gniadek C, Carr J, Conseil M, et al. Decreasing severe pain and serious adverse events while moving intensive care unit patients: a prospective interventional study (the NURSE-DO project). Crit Care. 2013;17:R74

10. Engström J, Bruno E, Reinius H, Fröjd C, Jonsson H, Sannervik J, et al. Physiological changes associated with routine nursing procedures in critically ill are common: an observational pilot study. Acta Anaesthesiol Scand. 2017:61:62-72.

11. Redaelli S, Zanella A, Milan M, Isgrò S, Lucchini A, Pesenti A, et al. Daily nursing care on patients undergoing venous-venous extracorporeal membrane oxygenation: a challenging procedure! J Artif Organs. 2016;19: 343-9.

12. Asfour HI. Oxygen desaturation and nursing practices in critically ill patients. IOSR JNHS. 2016. https://doi.org/10.9790/1959-05218594.

13. Arnal J-M, Wysocki M, Novotni D, Demory D, Lopez R, Donati S, et al. Safety and efficacy of a fully closed-loop control ventilation (IntelliVent-ASV(R)) in sedated ICU patients with acute respiratory failure: a prospective randomized crossover study. Intensive Care Med. 2012;38:781-7.

14. Lellouche F, Bouchard P-A, Simard S, L'Her E, Wysocki M. Evaluation of fully automated ventilation: a randomized controlled study in post-cardiac surgery patients. Intensive Care Med. 2013;39:463-71.

15. Clavieras N, Wysocki M, Coisel Y, Galia F, Conseil M, Chanques G, et al Prospective randomized crossover study of a new closed-loop contro system versus pressure support during weaning from mechanical ventilation. Anesthesiology. 2013;119:631-41.

16. Beijers AJR, Roos AN, Bindels AJGH. Fully automated closed-loop ventilation is safe and effective in post-cardiac surgery patients. Intensive Care Med. 2014;40:752-3

17. Arnal J-M, Garnero A, Novonti D, Demory D, Ducros L, Berric A, et al. Feasibility study on full closed-loop control ventilation (Intellivent-ASV) in ICU patients with acute respiratory failure: a prospective observational comparative study. Crit Care Lond Engl. 2013;17:R196.

18. Bialais $E$, Wittebole $X$, Vignaux $L$, Roeseler J, Wysocki M, Meyer J, et al. Closed-loop ventilation mode (Intellivent ${ }^{\circledR}$-ASV) in intensive care unit: a randomized trial of ventilation delivered. Minerva Anestesiol. 2016:82:657-68.

19. Arnal JM, Garnero A, Novotni D, Corno G, Donati SY, Demory D, et al. Closed loop ventilation mode in intensive care unit: a randomized controlled clinical trial comparing the numbers of manual ventilator setting changes. Minerva Anestesiol. 2018;84:58-67.

20. Arnal J-M, Saoli M, Garnero A. Airway and transpulmonary driving pressures and mechanical powers selected by INTELLiVENT-ASV in passive, mechanically ventilated ICU patients. Heart Lung J Crit Care. 2019. https:// doi.org/10.1016/j.hrtlng.2019.11.001.

21. Girardis M, Busani S, Damiani E, Donati A, Rinaldi L, Marudi A, et al. Effect of conservative vs conventional oxygen therapy on mortality among patients 
in an intensive care unit: the oxygen-ICU randomized clinical trial. JAMA. 2016;316:1583

22. O'Driscoll BR, Howard LS, Earis J, Mak V. British Thoracic Society Guideline for oxygen use in adults in healthcare and emergency settings. BMJ Open Respir Res. 2017;4:e000170.

23. Rivara D, Artucio H, Arcos J, Hiriart C. Positional hypoxemia during artificial ventilation. Crit Care Med. 1984;12:436-8.

24. Thomas PJ, Paratz JD, Lipman J, Stanton WR. Lateral positioning of ventilated intensive care patients: a study of oxygenation, respiratory mechanics, hemodynamics, and adverse events. Heart Lung. 2007;36:277-86.

25. Mezidi M, Guérin C. Effects of patients positioning on respiratory mechanics in mechanically ventilated ICU patients. Ann Transl Med. 2018;6(19):384.

26. Tanskanen P, Kytta J, Randell T. The effect of patient positioning on dynamic lung compliance. Acta Anaesthesiol Scand. 1997;41:602-6.

27. Maggiore SM, Lellouche F, Pigeot J, Taille S, Deye N, Durrmeyer X, et al. Prevention of endotracheal suctioning-induced alveolar derecruitment in acute lung injury. Am J Respir Crit Care Med. 2003;167:1215-24.

28. Oh H, Seo W. A meta-analysis of the effects of various interventions in preventing endotracheal suction-induced hypoxemia. J Clin Nurs. 2003;12: 912-24.

29. Fernández M-M, Piacentini E, Blanch L, Fernández R. Changes in lung volume with three systems of endotracheal suctioning with and without pre-oxygenation in patients with mild-to-moderate lung failure. Intensive Care Med. 2004:30:2210-5.

30. Gattinoni L, Tonetti T, Cressoni M, Cadringher P, Herrmann P, Moerer O, et al. Ventilator-related causes of lung injury: the mechanical power. Intensive Care Med. 2016;42:1567-75.

31. Singh AK, Sahi MS, Mahawar B, Rajpurohit S. Comparative evaluation of accuracy of pulse oximeters and factors affecting their performance in a tertiary intensive care unit. J Clin Diagn Res. 2017. https://doi.org/10.7860/ jcdr/2017/24640.9961.

\section{Publisher's Note}

Springer Nature remains neutral with regard to jurisdictional claims in published maps and institutional affiliations.

Ready to submit your research? Choose BMC and benefit from:

- fast, convenient online submission

- thorough peer review by experienced researchers in your field

- rapid publication on acceptance

- support for research data, including large and complex data types

- gold Open Access which fosters wider collaboration and increased citations

- maximum visibility for your research: over $100 \mathrm{M}$ website views per year

At $\mathrm{BMC}$, research is always in progress.

Learn more biomedcentral.com/submissions 